\title{
Medication adherence: process for implementation
}

This article was published in the following Dove Press journal:

Patient Preference and Adherence

28 July 2014

Number of times this article has been viewed

Phil Mendys ${ }^{1,2}$

Leah L Zullig ${ }^{3}$

Rebecca Burkholder ${ }^{4}$

Bradi B Granger ${ }^{5}$

Hayden B Bosworth $3,5,6$

'Pfizer Inc, Medical Affairs, New York, NY, USA; '2Division of Cardiology,

University of North Carolina, Chape Hill, NC, USA; ${ }^{3}$ Center for Health

Services Research in Primary Care,

Durham Veterans Affairs Medical

Center, Durham, NC, USA; ${ }^{4}$ ational

Consumers League, Washington,

DC, USA; ${ }^{5}$ School of Nursing,

Duke University, Durham, NC,

USA; ${ }^{6}$ Department of Medicine and

Psychiatry, School of Medicine, Duke

University, Durham, NC, USA
Correspondence: Phil Mendys

UNC Heart and Vascular Center, 300 Meadowmont Circle, Chapel Hill, NC 275 I7, USA

Tel + I 9199667200

Fax +l 6464416197

Email pmendys@unch.unc.edu
Abstract: Improving medication adherence is a critically important, but often enigmatic objective of patients, providers, and the overall health care system. Increasing medication adherence has the potential to reduce health care costs while improving care quality, patient satisfaction and health outcomes. While there are a number of papers that describe the benefits of medication adherence in terms of cost, safety, outcomes, or quality of life, there are limited reviews that consider how best to seamlessly integrate tools and processes directed at improving medication adherence. We will address processes for implementing medication adherence interventions with the goal of better informing providers and health care systems regarding the safe and effective use of medications.

Keywords: medication adherence, pharmacy, policy, health care systems, self-management, patient education

\section{Improving medication adherence - an important unmet need and process of care}

In the recently published National Community Pharmacists Association report on medication adherence, the cost of medication nonadherence in 2009 was estimated at $\$ 290$ billion in the US. ${ }^{1,2}$ In addition to cost issues, and perhaps more compelling, are the potential clinical ramifications of medication nonadherence. Safety issues and suboptimal patient outcomes associated with poor medication adherence are estimated to impact 133 million Americans with at least one chronic disease. ${ }^{3}$ There is an increasing business case for addressing medication nonadherence as payment and delivery system models evolve to place providers at risk for longitudinal patient outcomes and downstream costs (eg, bundled payments and accountable care organizations), providers' interest in care coordination and durable treatment inventions expand.

Ongoing policy changes have resulted in a greater focus on individuals and medication adherence. The Health Information Technology for Economic and Clinical Health Act passed in 2009 as part of the American Recovery and Reinvestment Act, for example, authorizes an estimated $\$ 30$ billion in incentives to eligible professionals and hospitals that adopt and meet federal standards for the meaningful use of certified electronic health record (EHR) technology. ${ }^{4}$ Meaningful use includes functions such as e-prescribing, reporting clinical quality measures, clinical decision support, and the electronic exchange of clinical messages between providers. The Health Information Technology for Economic and Clinical Health Act authorized another \$2 billion to develop and support the nation's health information technology (HIT) infrastructure and capacity to engage in the electronic exchange of health information. This included technical support for the adoption, maintenance, and meaningful use of EHR systems. Additionally, current Centers for Medicare and Medicaid Services Accountable Care 
Organization performance standards include: enhanced patient experience (often associated with provider-patient communication); chronic illness disease control; and provision of preventive services. Last, increased attention on patient medication adherence has occurred because of the new Medicare Advantage Part D five-star quality rating system for medication adherence for 2014, which has recently been issued requiring all health care plans to have a four or better rating. ${ }^{5}$ Health plans earning four or five out of five available stars can receive bonus payments to be used to enhance benefits or lower future plan premiums to attract additional members. As part of Medicare Advantage Part D five-star quality-rating system, adherence to medications for hypertension, diabetes, and cholesterol are routinely examined as part of the Drug Pricing and Patient Safety Program.

\section{The many facets of medication adherence - simplifying the equation}

Many factors account for poor medication adherence ranging from patient socioeconomic status to provider training. For example, existing models of chronic disease management ${ }^{6}$ and behavior change ${ }^{7}$ are informative, but our review takes a new approach. We combine the concepts of the health care system, patient and practice team from the Wagner Chronic Care Model, ${ }^{6}$ views from Michie et $\mathrm{al}^{7}$ such as regulations and service provision, and perspectives from our own work to create this process plan for implementation. For the purpose of the review, we present a holistic plan to address medication adherence, focusing on three core components: 1) patients; 2) providers; and 3) health care practices.

It is important to consider a few basic concepts. First, each patient is unique with specific clinical, educational and economic needs, and situational factors. Second, providers include physicians, nurses, pharmacists, or other allied health professionals who work collaboratively and contribute to care delivery. Last, for the purpose of this review, the terms "practice", "health care system", or the "health care plan" are interchangeable for this review, as the "system" must provide support to the providers and the patients in some meaningful way to address and improve the use of medicines as part of an overall treatment plan. These components form the critical relationship that drives engagement resulting in behavior change that will make a difference to improving medication adherence and patient outcomes (Figure 1). "Better information, communication, and patient support have been shown in previous studies to increase patients' engagement and involvement in their health care, their satisfaction."1 We begin with a case study and then discuss each component

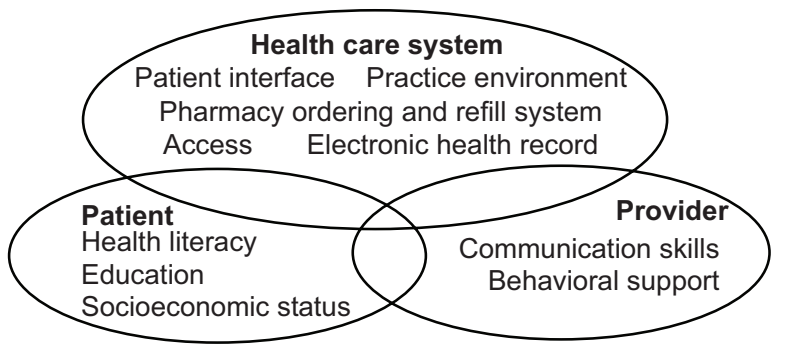

Figure I Simplified approach to improving medication adherence.

of the three core components (ie, patients, providers, and health care practices).

\section{Case study: anticoagulation in stroke risk reduction - current and future options}

In their recent study, Brown et al present a conceptual model for adherence to warfarin by combining insights from patient focus groups and a comprehensive literature review. ${ }^{8}$ As with any adherence challenge, this analysis looks at the multiple therapeutic and patient considerations to determine which influencers affect adherence to oral anticoagulation. This provides an overview of the multiple facets of improving adherence in anticoagulation. These are then replicated in our proposal for the emerging clinical coordination of patients with atrial fibrillation (AF); multiple influencers of medication use are brought together when a coordinated team-based approach is employed as outlined in our approach.

Based on the lessons learned, the process of adherence is impacted by: the patient's disease knowledge and ongoing support from the health care team; the balance between shortterm avoidance of adverse events (eg, bleeding) or longer-term benefits (eg, reduction of stroke risk); developing a routine with therapy that may include external reminders; and patient selfefficacy. So, indeed, the use of anticoagulation with warfarin in reducing the stroke risk associated with $\mathrm{AF}$ provides a compelling story of medication use, misuse, and nonadherence.

It is well-appreciated that warfarin provides an impressive risk reduction for stroke inpatients with $\mathrm{AF}$, particularly as the associated criteria of congestive heart failure, hypertension, age, diabetes, and prior stroke/transient ischemic attack - also known as the CHADS2 risk score- are included. ${ }^{9}$ The nonand underutilization of warfarin in patients with a diagnosis of AF is common and costly, according to a recent analysis by Casciano et al resulting in increased inpatient and total health care costs. ${ }^{10}$

It is generally accepted that only $50 \%$ of the patients who are eligible for warfarin are actually prescribed the drug for a 
variety of reasons. Most prominently, however, it is the consideration for the benefit of treatment versus the risk of major or minor bleeding events. ${ }^{11,12}$ There are often complex patient care considerations when using warfarin, such as bleeding, that necessitate monitoring. Anticoagulation clinics emerge as a way to address this problem. Patients develop consistent contact with a provider, are given comprehensive education about their illness and the treatment, and are expected to evaluate the care progress approximately once monthly. A challenge remains that only one-half of the patients prescribed warfarin in the US have access to specific clinical providers, as described previously. While the aforementioned specialized clinics improve warfarin utilization, challenges remain in terms of safety and nonadherence that are associated with warfarin use. Access to specialized services is limited, and - as published in 2011 - adverse event data from a national data set reveals that warfarin was most often implicated in the emergency hospitalization of adverse drug events. ${ }^{19}$ Ultimately, improving anticoagulant adherence issues will avoid harm and improve outcomes in an often at-risk patient population.

What are the key lessons and practices that might improve adherence to warfarin as well as the newer approaches to anticoagulation? If we understand that improved adherence results in a more stable treatment response and reduced variability in overall patient response, then how should we proceed? The quality of care associated by structured support to patients who are prescribed warfarin is quantified by the percentage of patients who were kept in the therapeutic range. Clinical services provided by the specialty care pharmacist both identified the ability to improve care quality as measured by time in the therapeutic range and also reduced anticoagulation-related emergency room visits and hospitalizations. ${ }^{13}$

Coagulation clinics are opting out of the traditional clinic and moving to a service line, focusing on $\mathrm{AF}$ and preventive services, which not only include the management of anticoagulation, but they also address common concurrent therapies, such as antiarrhythmic monitoring as well as common comorbidities associated with AF, including hypertension, diabetes, and coronary disease. These service lines can be managed by advanced practice clinicians, such as nurses or pharmacists, collaborating with both specialists and primary care physician providers. Thus, as in diabetes care, a range of services can be provided or coordinated by well-trained midlevel practitioners and address often complex patient needs and behaviors, inclusive of proper medication usage and adherence. ${ }^{14}$ As suggested in Table 2, a series of clinical issues or therapeutic challenges may be identified by a core/planning team who is responsible for identifying outputs. In this case, we also link educational support directed at the patient to - in part-address the therapeutic challenge and link inclusion into the medical record for verification across clinical services. Last, items of measurement need to be attached as part of focused quality improvement process in support of improved medication adherence.

\section{Case study: HIT and lipid management}

In a recently published analysis encompassing 34 trials with more than 84,000 enrolled patients, the impact of HIT to address quality gaps, including medication adherence, was evaluated in patients who required lipid management. ${ }^{15,16}$ HIT intervention processes (eg, screening, testing, drug initiation, titration, adherence, and/or referrals) were evaluated. Although a range of effects was found, more than one-third of the studies determined that an HIT intervention could impact outcomes. A core principle of this analysis was that the tools employed need to provide connectivity of the patient to the health care systems, as well as targeting providers and systems to improve lipid treatment, adherence, and quality. While any number of interventions may provide short-term value - particularly in practices and populations with low baseline adherence and low-density lipoprotein cholesterol control as a baseline consideration - long term effects may depend on longer-term support and follow-up as allocated in the study design. Ultimately, intervention modalities that connect patients to the health care system may be more likely to provide practices with an unappreciated resource to improve lipid management, including adherence and low-density lipoprotein cholesterol

Table I Connectedness of patient, provider, and health care system

\begin{tabular}{llll}
\hline Patient & Provider(s) & Health care system \\
\hline - & Patient needs information and dialogue & Provider or team must provide information & System must enable access for patient to \\
with providers to clarify preferences and & to patient in a sensitive and meaningful way, & secure services and support clinical team \\
assimilate learning from the provider & such that the patient is enabled to make & to optimize patient care through education, \\
encounter into a relevant plan for self-care & shared decisions and is involved in care plan. & compassion, and continuity of care. \\
(shared decision-making). & &
\end{tabular}


control, resulting in a more patient-centric approach to disease management and treatment support.

\section{Patient, provider, and health care system}

The patient enters the health care system based on a wide range of possible circumstances - be it symptoms of a disease, preventive services, or often-unspecified concerns about their health or well-being. These encounters are also influenced by the nature of a practice environment, ranging from a primary care orientation to specialized clinical services, where there may be not only a unique focus on clinical issues (eg, cardiovascular disease), but also access to a broader range of clinical providers, such as nurses, pharmacists, cardiac rehabilitation professionals, and others who engage with the patient in addition to the physician. Each of these types of providers may bring a unique skill-set and perspective. For example, in the US, clinical pharmacists may be specially trained experts in medication monitoring $;{ }^{17}$ in other countries, the role of pharmacists may be even greater. Consider the concept of the patient-centered medical home, where there is an increased level of support from HIT and decision support, continuity and coordination of care, and accountability by the health care system - all which emphasize a patient-focused and team-based approach to health care delivery. ${ }^{18}$ By adapting this model across the health care system, we can achieve connected and accountable care for patients that includes the appropriate use of medications (Table 1).

\section{Transition to principles of medication adherence}

Once the case to improve adherence has been made, what might a practice do to develop a medication adherence improvement plan? Given the many challenges within the delivery of health care, including time, patient-specific resources, and lack of adequate reimbursement, the ability to further incorporate medication management as a component of care becomes even more challenging. Given that the problem of poor medication adherence is multifactorial, effective medication adherence programs need to adopt an approach that involves several proven strategies. Several evidence reviews have identified interventions effective in promoting both overall and condition-specific medication adherence. ${ }^{19-21}$ While no universal formula will improve medication adherence in all settings, several ingredients are essential for any well-designed medication adherence improvement intervention. These ingredients include: improving patients' understanding of their treatments; providing counseling and accountability by the health care team; ensuring that there are tools and strategies to assist patient self-monitoring; and increasing access to affordable medications. ${ }^{21}$ There is a strong evidence base showing that the interventions that increase the patients' knowledge

Table 2 Process to evolve clinical services in AF

\begin{tabular}{|c|c|c|c|c|}
\hline $\begin{array}{l}\text { Identify therapeutic } \\
\text { challenge }\end{array}$ & $\begin{array}{l}\text { Establish team and } \\
\text { deliverables }\end{array}$ & $\begin{array}{l}\text { Patient education and } \\
\text { support }\end{array}$ & Integration of IT & Measurement \\
\hline $\begin{array}{l}\text { Underuse of standard } \\
\text { anticoagulation with } \\
\text { warfarin }\end{array}$ & $\begin{array}{l}\text { Apply lessons learned } \\
\text { from coordinated care } \\
\text { model }\end{array}$ & $\begin{array}{l}\text { Modify content for patient } \\
\text { education based on new } \\
\text { service model }\end{array}$ & $\begin{array}{l}\text { Adjust inputs in EHR } \\
\text { beyond warfarin clinic } \\
\text { support }\end{array}$ & $\begin{array}{l}\text { Continue to identify } \\
\text { appropriate patients } \\
\text { who benefit from } \\
\text { anticoagulation therapy } \\
\text { based on risk criteria }\end{array}$ \\
\hline $\begin{array}{l}\text { Emergence of newer } \\
\text { anticoagulation }\end{array}$ & $\begin{array}{l}\text { Translate focus of AF } \\
\text { management to newer } \\
\text { treatment options }\end{array}$ & $\begin{array}{l}\text { Determine specific } \\
\text { messages on range } \\
\text { of options for } \\
\text { anticoagulation therapy }\end{array}$ & $\begin{array}{l}\text { Update EHR and smart } \\
\text { sets to address current } \\
\text { patient needs }\end{array}$ & $\begin{array}{l}\text { Compare results from } \\
\text { clinical trials to compare } \\
\text { translation of potential } \\
\text { benefit and harm }\end{array}$ \\
\hline $\begin{array}{l}\text { Limited access of } \\
\text { anticoagulation services }\end{array}$ & $\begin{array}{l}\text { Expand clinical services } \\
\text { to include vascular } \\
\text { disease prevention often } \\
\text { associated with AF }\end{array}$ & $\begin{array}{l}\text { Expand access to include } \\
\text { anticoagulation services, } \\
\text { medication management, } \\
\text { and vascular prevention }\end{array}$ & $\begin{array}{l}\text { Broaden focus to include } \\
\text { electrophysiology and } \\
\text { general cardiology } \\
\text { within a given practice } \\
\text { environment }\end{array}$ & $\begin{array}{l}\text { Determine value of AF } \\
\text { and vascular prevention } \\
\text { clinic across services } \\
\text { within a cardiology } \\
\text { practice }\end{array}$ \\
\hline $\begin{array}{l}\text { Management of newer } \\
\text { agents that may not } \\
\text { require monitoring and } \\
\text { monthly visits }\end{array}$ & $\begin{array}{l}\text { Develop a schema } \\
\text { for nonwarfarin } \\
\text { anticoagulants and } \\
\text { expand clinical services }\end{array}$ & $\begin{array}{l}\text { Base patient visits on } \\
\text { individual patient need and } \\
\text { associated comorbidities }\end{array}$ & $\begin{array}{l}\text { Set standards of care in } \\
\text { AF patient population } \\
\text { based on more } \\
\text { comprehensive approach } \\
\text { to care }\end{array}$ & $\begin{array}{l}\text { Determine options } \\
\text { to address improved } \\
\text { overall outcomes as } \\
\text { well as patient safety } \\
\text { and satisfaction }\end{array}$ \\
\hline
\end{tabular}


of medication $\mathrm{s}^{22}$ and support behavioral change - coupled with medication management $t^{23}$ - are effective at improving medication adherence.

\section{Approaching patient, practice, and provider - the adherence triad}

Building upon the three components of the health care schema - the patient, the provider, and the practice - we now develop the concept of the adherence triad (Figure 2). The provider role is central to achieving buy-in and process improvement, keeping treatment regimens simple and focused. Provider behavior change is reflected in the actions necessary to impact medication use. Training in the areas of health literacy, motivational interviewing, and information technology is useful for health care professionals to help educate and support their patients. The patient has a role to engage on different levels: with personal knowledge and support systems; with the provider before, during, and after the encounter; and the system to navigate and facilitate their own care success. The practice (system) has a role to encourage an environment where all the stakeholders understand the end game and provide simple seamless support mechanisms to improve patient care, outcomes, and satisfaction with the provision of care.
There are two keys to engagement for all members of the adherence triad. These are simplicity and fluidity. First and foremost, keep it simple. The responsibilities of each member of the adherence triad must be clearly articulated and understood. Ownership for each activity, the timing of it, and how it will be measured is vital to ensure that the patient care objectives are met. There must be fluid twoway communication between all parties to ensure effective communication. The communication continuum should be nondisruptive and should seamlessly integrate into a given practice environment. The assessment of goals and objectives is important to know whether all triad members are engaged and to make adjustments in real-time as needed. Each member of the triad should know what is expected and how best to evaluate success in meeting the long-term goals of success.

There are several key questions that must be considered when evaluating success. For example, is the evaluation of success comparable between the patient and their provider? How can the provider ensure the plan is understood and accepted by the patient? How can the patient, including his family and caregivers, be sure that the provider understood his priorities, challenges, and goals for treatment? How

\section{Adherence triad \\ $\underline{\text { WHO }}$ does WHAT, and $\underline{\mathrm{HOW}}$ is it measured?}

\begin{abstract}
Supported by the practice environment, the provider(s) take responsibility to outline a plan to support improved medication adherence.
\end{abstract}

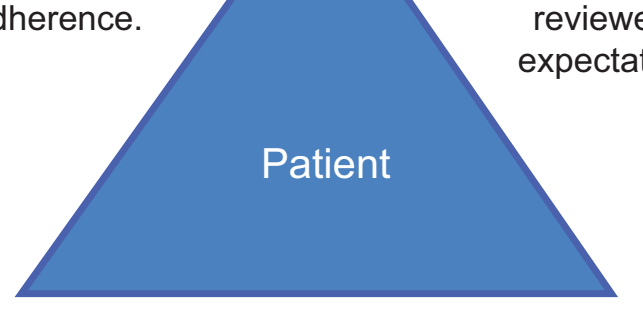

Patient-focused education about disease issues, treatment options, and tools that may assist the patient are reviewed. Set and manage expectations of the care plan.

Follow-up and keeping patient engagement are critical. Ensuring access to medication HIT support, use of websites, and patient empowerment strategies must be purposefully designed with the ability to assess over time.

Figure 2 Adherence triad. 
does the health care system maintain a process of ongoing quality improvement? There are many possible answers to the questions and no one-size-fits all solution. The tools and resources must be selected, based on the specific practice environment.

\section{Tools and resources}

The triad must organize tools and resources to facilitate medication adherence with a specific eye toward the unique needs of the patient. Patient education and methods for addressing modifiable patient-level factors that may influence adherence, such as health literacy, must be addressed. There are many patient educational resources - including medication instruction sheets, personalized medication calendars, streamlined pictorial bottle labels, and simple reminder systems - that can inform patients about their medication at a level aligned with their health literacy level. ${ }^{24,25}$ Technology provides many tools and resources that may facilitate improved adherence, including pill monitoring systems, mobile health technology, online resources, social media, and electronic health records, among others. ${ }^{26}$

Harnessing technology can also impact the frequency of patient-provider contact and ensure accountability. While there is no one universally established solution to foster proper medication adherence, HIT can inform numerous strategies to monitor adherence and improve rates, to inform patients' self-management, health care service planning, and health policy decision making. Studies are increasingly demonstrating that the use of IT can improve health outcomes and facilitate improvements in the quality and the coordination of care. ${ }^{19,20}$ Two common examples of HIT are e-prescribing, or the electronic generation of a prescription and its process for being filled at a pharmacy, and EHR systems.

When medication adherence tools and resources are used by the patient, understood by the provider, and endorsed by the practice, they form an important part of the plan to improve medication use. Through the adoption of HIT solutions, adherence tools can also be used to ensure accountability of the triad both internally to its own members and externally to the broader health care delivery system. This can be used to inform a learning health care organization focused on continuous quality improvement.

\section{Concluding remarks: plans to implement a medication adherence program}

When developing and implementing a medication adherence improvement program, it is important that providers and health care systems consider three key questions. Have you identified medication adherence as a priority within your practice or organization? How do you want to affect medication use in your patient (population)? What are the available resources in terms of people, process, and investments to achieve your medication adherence goals? To examine these issues, providers and health care systems may form a working group to further evaluate the components of care within their specific practice environment. It is important to assess the available resources relative to the objectives in developing a plan; start small, perhaps focusing on specific patient population, disease area, or clinic space. Finally, be certain to incorporate a quality improvement approach at the onset of the program to measure, monitor, and adapt the program to meet potentially evolving patient care objectives. The Supplementary materials provide specific examples of web-based quality improvement agencies and resources, such as the Agency for Healthcare Quality and Research - Innovations Exchange and Pharmacy Quality Alliance (Figure S2).

\section{Disclosure}

The authors have no conflicts of interest to declare in respect of this work.

\section{References}

1. National Community Pharmacists Association. Medication Adherence in America: A National Report 2013. Alexandria, VA; National Community Pharmacists Association; 2013. Available from: http://www. ncpanet.org/pdf/reportcard/adherencereportcard_abridged.pdf. Accessed December 11, 2013.

2. New England Healthcare Institute. Thinking Outside the Pillbox: A System-wide Approach to Improving Patient Medication Adherence For Chronic Disease. Cambridge, MA; New England Health Care Institute; 2009. Available from: http://adhereforhealth.org/ wp-content/uploads/pdf/ThinkingOutsidethePillbox_Report.pdf. Accessed January 14, 2014.

3. Roebuck MC, Liberman JN, Gemmill-Toyama M, Brennan TA. Medication adherence leads to lower health care use and costs despite increased drug spending. Health Aff (Millwood). 2011;30(1):91-99.

4. Blumenthal D, Tavenner M. The "meaningful use" regulation for electronic health records. $N$ Engl J Med. 2010;363(6):501-504.

5. Medicare.gov. [homepage on the Internet]. Plan Quality and Performance Ratings. Centers for Medicare and Medicaid Services; 2014. Available from: http://www.medicare.gov/find-a-plan/results/ planresults/planratings/compare-plan-ratings.aspx?plantype=mapd. Accessed March 9, 2014.

6. Wagner EH. Chronic disease management: what will it take to improve care for chronic illness? Eff Clin Pract. 1998;1(1):2-4.

7. Michie S, van Stralen MM, West R. The behaviour change wheel: a new method for characterising and designing behaviour change interventions. Implement Sci. 2011;6:42.

8. Brown TM, Siu K, Walker D, Pladevall-Vila M, Sander S, Mordin M. Development of a conceptual model of adherence to oral anticoagulants to reduce risk of stroke in patients with atrial fibrillation. J Manag Care Pharm. 2012;18(5):351-362. 
9. Lip GY, Frison L, Halperin JL, Lane DA. Comparative validation of a novel risk score for predicting bleeding risk in anticoagulated patients with atrial fibrillation: the HAS-BLED (Hypertension, Abnormal Renal/ Liver Function, Stroke, Bleeding History or Predisposition, Labile INR, Elderly, Drugs/Alcohol Concomitantly) score. J Am Coll Cardiol. 2011;57(2):173-180.

10. Casciano JP, Dotiwala ZJ, Martin BC, Kwong WJ. The costs of warfarin underuse and nonadherence in patients with atrial fibrillation: a commercial insurer perspective. J Manag Care Pharm. 2013;19(4): 302-316.

11. Choudhry NK, Anderson GM, Laupacis A, Ross-Degnan D, Normand SL, Soumerai SB. Impact of adverse events on prescribing warfarin in patients with atrial fibrillation: matched pair analysis. $B M J$ 2006;332(7534):141-145.

12. Srivastava A, Hudson M, Hamoud I, Cavalcante J, Pai C, Kaatz S. Examining warfarin underutilization rates in patients with atrial fibrillation: Detailed chart review essential to capture contraindications to warfarin therapy. Thromb J. 2008;6:6.

13. Rudd KM, Dier JG. Comparison of two different models of anticoagulation management services with usual medical care. Pharmacotherapy. 2010;30(4):330-338.

14. Heidbuchel H, Verhamme P, Alings M, et al; European Heart Rhythm Association. European Heart Rhythm Association Practical Guide on the use of new oral anticoagulants in patients with non-valvular atrial fibrillation. Europace. 2013;15(5):625-651.

15. Aspry KE, Furman R, Karalis DG, et al. Effect of health information technology interventions on lipid management in clinical practice: a systematic review of randomized controlled trials. J Clin Lipidol. 2013;7(6):546-560.

16. Schedlbauer A, Davies P, Fahey T. Interventions to improve adherence to lipid lowering medication [review]. Cochrane Database Syst Rev. 2010;3:CD004371.

17. Santschi V, Chiolero A, Burnand B, Colosimo AL, Paradis G. Impact of pharmacist care in the management of cardiovascular disease risk factors: a systematic review and meta-analysis of randomized trials. Arch Intern Med. 2011;171(16):1441-1453.
18. Carrier E, Gourevitch MN, Shah NR. Medical homes: challenges in translating theory into practice. Med Care. 2009;47(7):714-722.

19. Buntin MB, Burke MF, Hoaglin MC, Blumenthal D. The benefits of health information technology: a review of the recent literature shows predominantly positive results. Health Aff (Millwood). 2011;30(3):464-471.

20. Cebul RD, Love TE, Jain AK, Hebert CJ. Electronic health records and quality of diabetes care. N Engl J Med. 2011;365(9):825-833.

21. Zullig LL, Peterson ED, Bosworth HB. Ingredients of successful interventions to improve medication adherence. JAMA. 2013 310(24):2611-2612

22. Gwadry-Sridhar FH, Manias E, Lal L, et al. Impact of interventions on medication adherence and blood pressure control in patients with essential hypertension: a systematic review by the ISPOR medication adherence and persistence special interest group. Value Health. 2013;16(5):863-871.

23. Kripalani S, Yao X, Haynes RB. Interventions to enhance medication adherence in chronic medical conditions: a systematic review. Arch Intern Med. 2007;167(6):540-550.

24. Gossey JT, Whitney SN, Crouch MA, Jibaja-Weiss ML, Zhang H, Volk RJ. Promoting knowledge of statins in patients with low health literacy using an audio booklet. Patient Prefer Adherence. 2011; 5:397-403.

25. Zullig LL, McCant F, Melnyk SD, Danus S, Bosworth HB. A health literacy pilot intervention to improve medication adherence using Meducation $^{\circledR}$ technology. Patient Educ Couns. 2014;95(2):288-291.

26. Zullig LL, Shaw RJ, Bosworth HB. The Application of Technology to Medication Management and Adherence. In: Marsch L, Lord S, Dallery J, eds. Leveraging Technology to Transform Behavioral Healthcare. New York: Oxford University Press. In press 2014. 


\section{Supplementary materials}

\section{Review of adherence-related websites Adult Meducation: Improving Medication Adherence in Older Adults}

Available at: http://www.adultmeducation.com/

The American Society on Aging (ASA) and the American Society of Consultant Pharmacists (ASCP) Foundation have collaborated on the development of Adult Meducation: Improving Medication Adherence in Older Adults, a web-based program (Figure S1) to educate ASA and ASCP members on important aspects of medication adherence in older adults. One goal of the program is to encourage ASA members to work together with ASCP member pharmacists to identify, resolve, and prevent medication nonadherence in the older adults served by community-based service providers. This website contains:

- Information on factors that influence medication adherence, barriers to adherence, and specific strategies to improve adherence

- Tools to identify older adults at risk for medication nonadherence

- Resources to improve medication adherence

- Materials to educate older adults about the importance of medication adherence

- Educational programs targeted at community-based service providers and health professionals

- Links to other useful web resources

- Materials on the website that can be copied or downloaded for use in educational or training programs

\section{Agency for Healthcare Quality and Research - Innovations Exchange}

Available at: http://innovations.ahrq.gov/index.aspx

In addition to user tools and project descriptions on a wide range of clinical issues, the website (Figure S2) provides

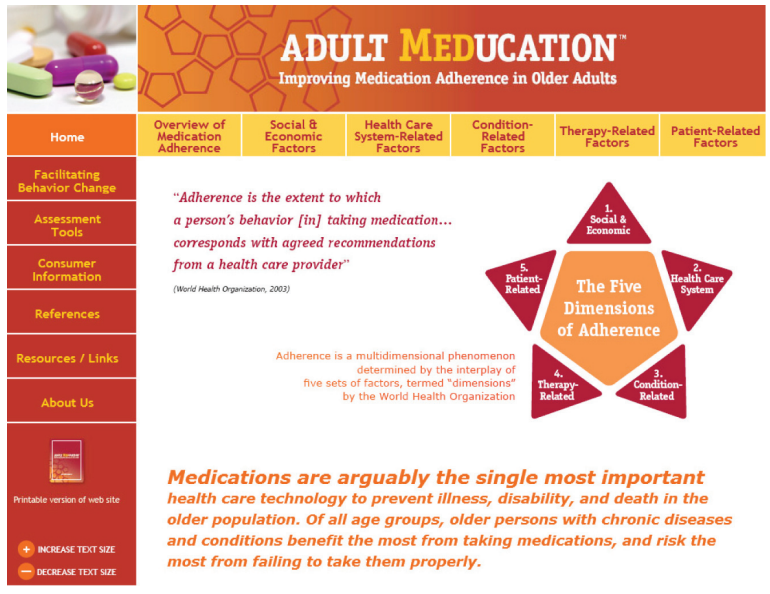

Figure SI Adult Meducation: Improving Medication Adherence in Older Adults.

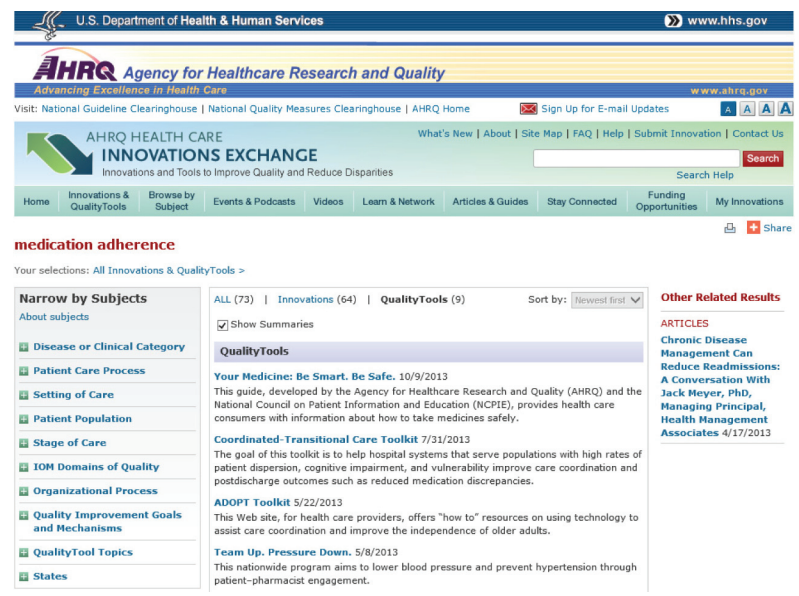

Figure S2 Agency for Healthcare Quality and Research - Innovations Exchange.

specific tools and research summaries in the area of medication adherence, which can be utilized by clinicians and researchers alike.

\section{American College of Preventive Medicine}

Available at: http://www.acpm.org/

The American College of Preventive Medicine provides a website (Figure S3) directed at providers to educate about the complex challenges of medication adherence with an additional summary of resources and tools, which may be incorporated into the practice environment.

\section{Script Your Future}

Available at: http://www.scriptyourfuture.org/

The Script Your Future campaign is a national public education campaign developed to raise awareness among patients, their family caregivers and health care professionals, about the importance of taking medications as directed. The

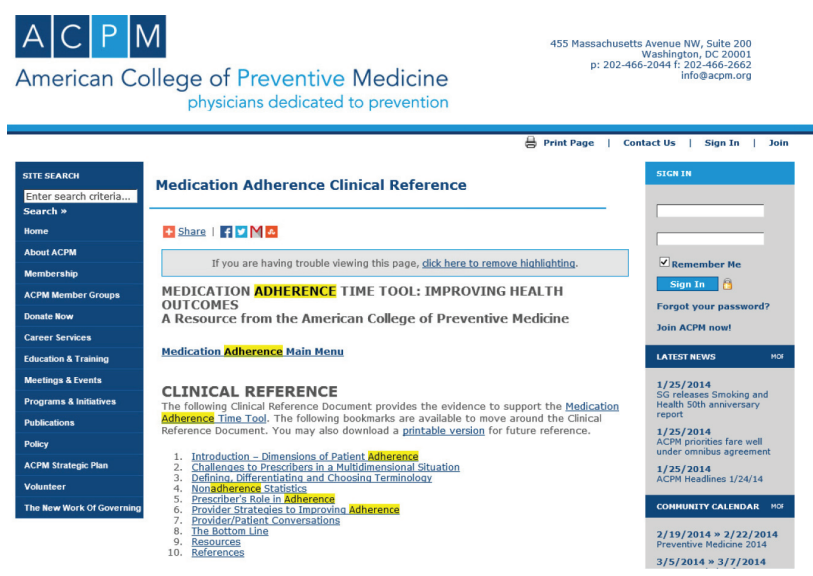

Figure S3 American College of Preventive Medicine. 


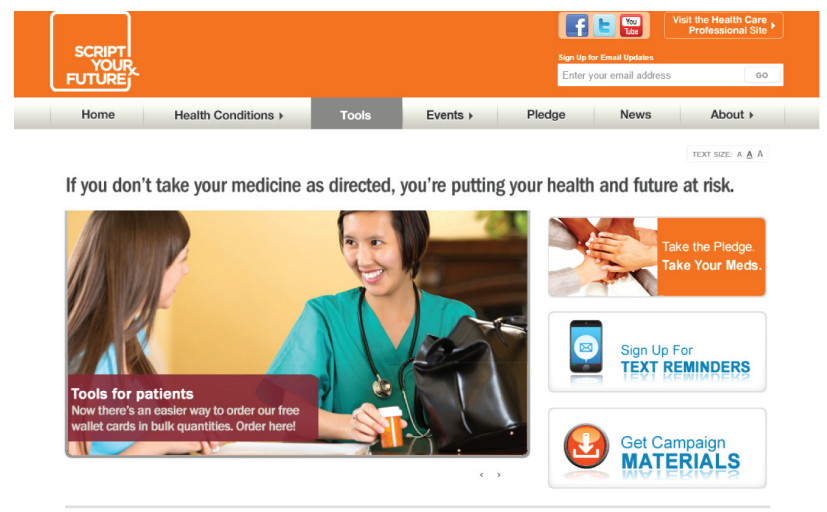

Figure S4 Script Your Future.

campaign, led by the National Consumers League, focuses on patients affected by three serious chronic conditions diabetes, respiratory disease, and cardiovascular disease. Script Your Future educates patients about the consequences of poor adherence, encourages patients and health care professionals to better communicate about medication, and offers tools and resources to help improve adherence. The interactive Script Your Future website (Figure S4), offers tools for both patients and health care professionals, including fact sheets on chronic conditions, charts to keep track of medications, videos, sample questions, text message alerts, and more.

Launched in May 2011, this unique three-year national campaign has targeted outreach efforts in: Baltimore, MD, USA; Birmingham, AL, USA; Cincinnati, OH, USA; Providence, RI, USA; Raleigh, NC, USA; and Sacramento, CA, USA. In addition to the website, the integrated campaign includes public service announcements, material dissemination, social media presence, health professions, and student out-reach activities. Script Your Future is supported by a coalition of more than 130 public and private partners.

\section{National Council on Patient Information and Education}

Available at: http://www.talkaboutrx.org/

Founded in 1982, the National Council on Patient Information and Education (NCPIE), located in Rockville, MD, USA, is a nonprofit multistakeholder coalition working to stimulate and improve the communication of information on the appropriate use of medicines to consumers and health care professionals. NCPIE, since its beginning, has strongly advocated for the medicine education team - considering the patient the key player. NCPIE develops and provides valuable patient education programs and educational resources promoting the latest advances in communication research



Figure S5 National Council on Patient Information and Education.

and practice. NCPIE's public-facing websites (Figure S5) include: talkaboutrx.org; bemedicinesmart.org; bemedwise. org; mustforseniors.org; and recoveryopensdoors.org

NCPIE works to address critical medicine safe use issues like adherence improvement, prescription drug abuse prevention, treatment and recovery, medication error reduction, quality improvements in health care provider-patient medicine communication, and safe storage and disposal of medicines.

With mounting evidence that poor medicine adherence will increase dramatically with the projected rise in agerelated chronic illnesses, NCPIE released a nationwide call to action - the Accelerating Progress in Prescription Medicine Adherence: The Adherence Action Agenda (October 2013) that places a spotlight on the pervasive and costly problem of poor medicine adherence, particularly among those age 65 and older with multiple chronic conditions, who are at the greatest risk of medication errors, drug interactions, and costly disease complications.

\section{North Carolina Program on Health Literacy}

Available at: http://www.nchealthliteracy.org/

Health literacy is defined as the degree to which individuals have the capacity to obtain, process, and understand basic health information and services needed to make appropriate health decisions. The concept of health literacy differs from literacy itself. Health literacy requires basic reading skills, but it also requires the ability to understand oral communication, use numbers and math skills, understand how to navigate the health system on a basic level as well as the ability to communicate with health care providers and their staff. To that end, the University of North Carolina School of Public Health has provided an extensive list of tools and resources 


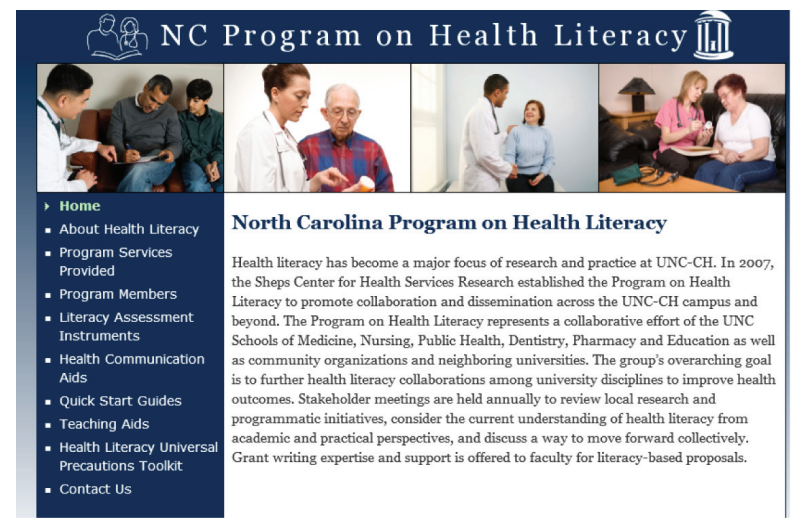

Figure S6 North Carolina Program on Health Literacy.

to help clinicians better understand and implement good practices of health literacy (Figure S6).

\section{Pharmacy Quality Alliance}

Available at: http://www.pqaalliance.org

Established in 2006, the Pharmacy Quality Alliance is a 501(c)(3) designated nonprofit alliance with more than 100 member organizations (Figure S7). The Pharmacy Quality Alliance is a multistakeholder, consensus-based membership organization that collaboratively promotes appropriate medication use and develops strategies for measuring and

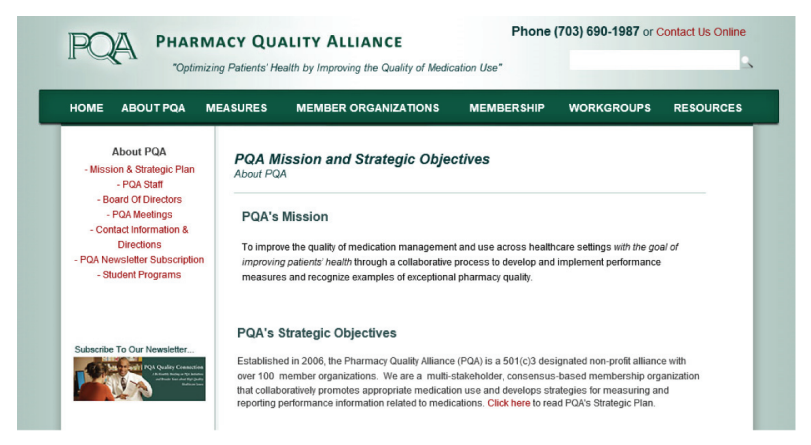

Figure S7 Pharmacy Quality Alliance. reporting performance information related to medications. Their mission statement is clear:

To improve the quality of medication management and use across healthcare settings with the goal of improving patients' health through a collaborative process to develop and implement performance measures and recognize examples of exceptional pharmacy quality.

\section{National Patient Safety Foundation (NPSF)}

Available at: http://www.npsf.org/about-us/

The NPSF's vision is to create a world where patients and those who care for them are free from harm. A central voice for patient safety since 1997, NPSF partners with patients and families, the health care community, and key stakeholders to advance patient safety and health care workforce safety and disseminate strategies to prevent harm. NPSF is an independent, not-for-profit 501(c)(3) organization. Among their resources is a unique clinician-patient interface tool called Ask Me 3 (Figure S8), which allows a quick effective engagement with patients regarding medication adherence.

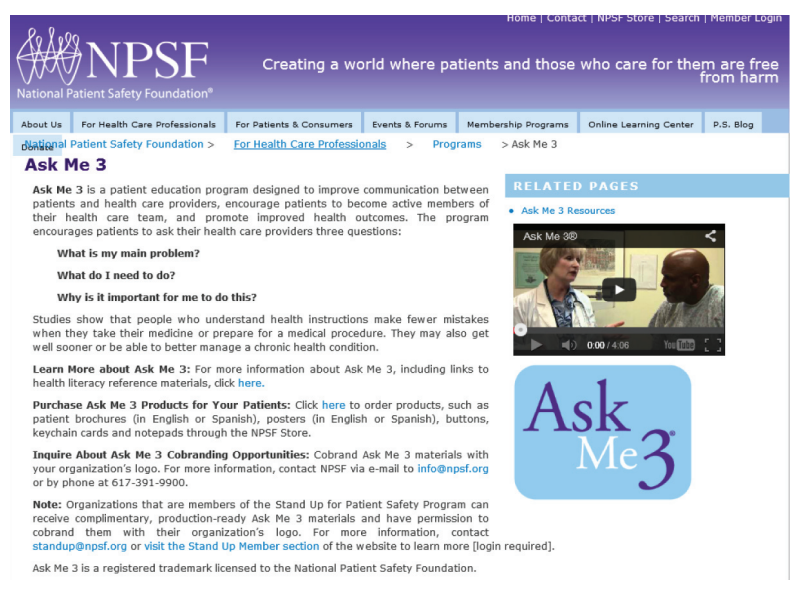

Figure S8 National Patient Safety Foundation.
Patient Preference and Adherence

\section{Publish your work in this journal}

Patient Preference and Adherence is an international, peer-reviewed, open access journal that focuses on the growing importance of patient preference and adherence throughout the therapeutic continuum. Patient satisfaction, acceptability, quality of life, compliance, persistence and their role in developing new therapeutic modalities and compounds to optimize

\section{Dovepress}

clinical outcomes for existing disease states are major areas of interest for the journal. This journal has been accepted for indexing on PubMed Central. The manuscript management system is completely online and includes a very quick and fair peer-review system, which is all easy to use. Visit http://www. dovepress.com/testimonials.php to read real quotes from published authors. 